\title{
General Psychiatry Psychiatric disorders associated with intimate partner violence and sexual violence in Thai women: Aresult from the Thai National Mental Health Survey
}

\author{
Benjaporn Panyayong, ${ }^{1}$ Nopporn Tantirangsee, ${ }^{2}$ Rudy R D Bogoian, ${ }^{3}$ the Thai \\ National Mental Health Survey Team 2013
}

To cite: Panyayong B, Tantirangsee N, Bogoian RRD, et al. Psychiatric disorders associated with intimate partner violence and sexual violence in Thai women: Aresult from the Thai National Mental Health Survey. General Psychiatry 2018;31:e000008. doi:10.1136/ gpsych-2018-000008

Received 28 September 2017 Revised 24 February 2018 Accepted 12 March 2018

\section{Check for updates}

(C) Author(s) (or their employer(s)) 2018. Re-use permitted under CC BY-NC. No commercial re-use. See rights and permissions. Published by BMJ.

${ }^{1}$ Somdetchaopraya Institute of Psychiatry, Khlong San, Thailand ${ }^{2}$ Department of Mental Health, Songkhla Rajanagarindra Psychiatric Hospital, Khlong San, Thailand

${ }^{3}$ Psychiatric Clinic, Ann Arbor, Michigan, USA

Correspondence to Benjaporn Panyayong; bpanyayong@gmail.com

\section{ABSTRACT}

Background Intimate partner violence (IPV) and sexual violence (SV) occur commonly and are a violation of basic human rights. There are limited studies to date that examine the impact of IPV, SV and mental health outcomes in Thailand.

Aims The objective of the present study was to estimate the prevalence of intimate partner physical violence and IPV in Thai women and the association between these forms of violence and psychiatric disorders.

Methods The present study used data from a national cross-sectional, population-based, household design survey. This study analysed data from 3009 female respondents above the age of 18 who were interviewed in person using the World Mental Health-Composite International Diagnostic Interview V.3.0 (WMH-CIDI 3.0). We estimated the lifetime and the 12-month period prevalence of IPV and SV, the lifetime and the past 12- month period correlation of IPV/SV with psychiatric disorders and the OR for psychiatric disorders associated with these types of violence.

Results There was only $5.2 \%$ of the weighted sample that reported experiencing some form of violence, including reported rates of intimate partner physical violence of $3.5 \%$ and IPV of $2.0 \%$. Women who had experienced IPV have a lifetime prevalence for common psychiatric disorders of $28.9 \%$, for suicidal behaviours of $12.2 \%$ and for substance use disorders of $8.8 \%$. Women who had experienced SV have a lifetime diagnoses for common psychiatric disorders of $21.4 \%$, for suicidal behaviours of $16.5 \%$ and for substance use disorders of $19.4 \%$. There was a statistically significant association between IPV/SV and being diagnosed with a psychiatric disorder during the past year and also during one's lifetime.

Conclusion The association between IPV/SV and psychiatric disorders is significant; therefore, performing a formal assessment for a history of violence in psychiatric patients is often beneficial in refining the diagnosis and treatment.

\section{INTRODUCTION}

Intimate partner physical violence (IPV) and sexual violence (SV) are increasing global public health concerns. ${ }^{1}$ The use of healthcare services has increased as a consequence of physical and psychiatric illness in association with IPV and SV, both on a shortterm and long-term basis, as compared with those not exposed to violence. ${ }^{2}$ In addition, the impact of violence can lead to functional impairment and lethal outcomes.

Globally, prevalence estimates of experiencing physical or sexual IPV in women alone, or in combination, varied from $15 \%$ to $71 \%$, yielding an average prevalence of $37 \%$. In Thailand, the lifetime prevalence of physical or sexual IPV or both among women has previously been reported as $41.1 \%$ in urban communities and as $47.4 \%$ in rural communities. ${ }^{3}$ A global report on homicide showed that intimate partner and family-related homicides ranged from $8.6 \%$ to $39.3 \%$ of all homicides by region. ${ }^{4}$

During the last two decades, a number of studies have reported that interpersonal violence (including IPV and SV) has increased significantly. The consequences impacting mental health from violence include depressive disorders, post-traumatic stress disorder (PTSD), anxiety disorders, substance use disorders, eating disorders, sleep disorders and suicide..$^{5-7}$

Previously, there were very few studies on the prevalence of IPV, SV and mental health consequences in Thailand. ${ }^{89}$ It is important to have a better understanding of the burdens caused by IPV and SV in order to develop, improve and refine public health policy, intervention and planning.

\section{METHODS}

The present study used data from a 2013 cross-sectional household national survey in the general population. As shown in figure 1, the sample was selected using a stratified 


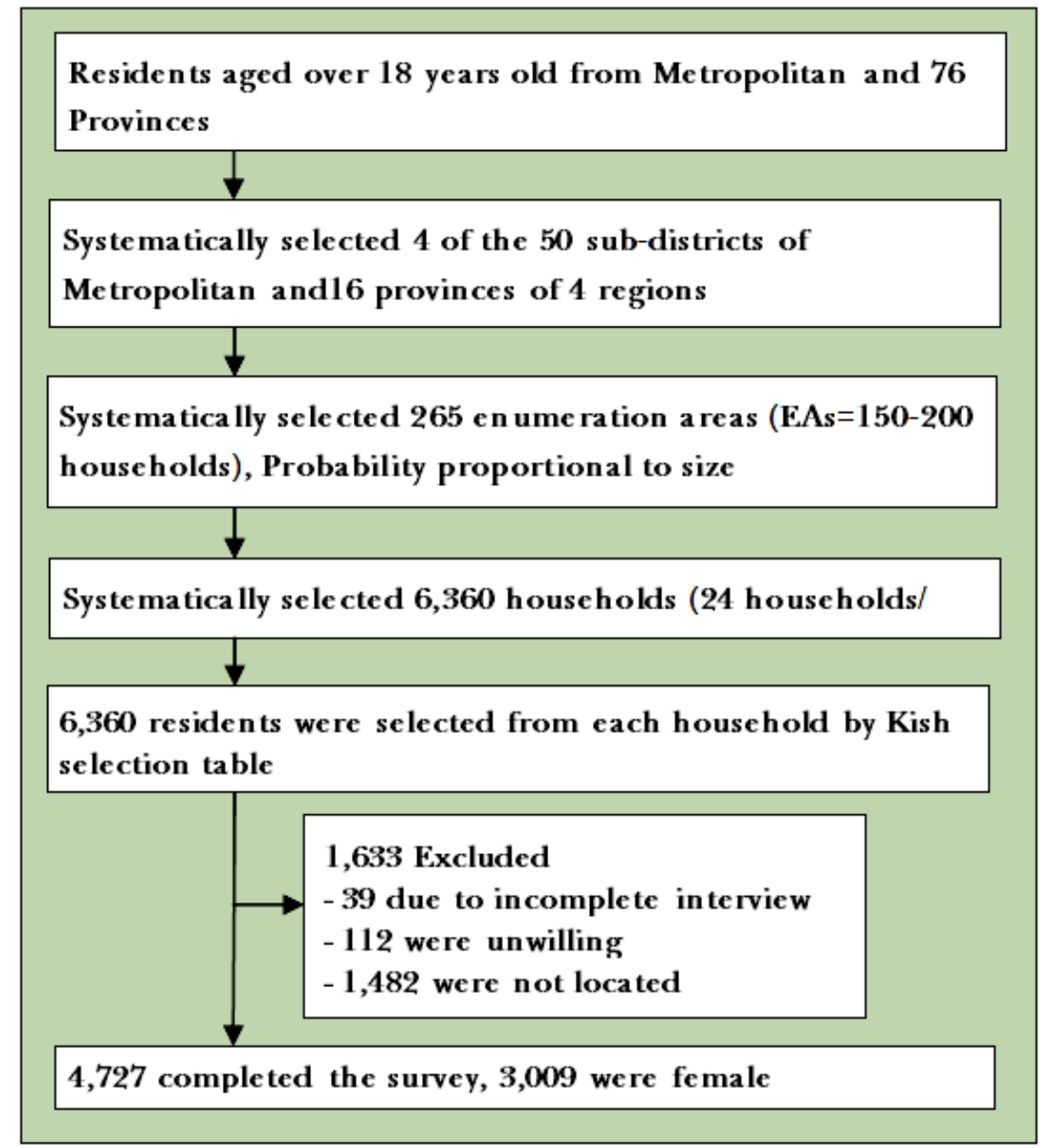

Figure 1 Identification of survey participants.

four-stage probability sampling procedure. The first stage involved the systematic selection of primary sampling units from Bangkok and four regions. The second stage involved the selection of secondary units based on Consensus Enumeration Areas. The third stage involved the sampling of housing units within clusters selected within each area. The fourth stage involved the systematic selection of one adult respondent in each sampled household by using the grid method of Kish. Four thousand seven hundred and twenty-seven eligible residents from 6360 households, aged over 18 years completed a face-to-face interview by field interviewers. Non-respondents included refusals and failure to contact study subjects (three attempts were made to contact respondents by field interviewers). The majority of non-respondents were due to failure to contact the individual, while relatively few refusals were encountered. The response rate was $74.3 \%$. Of the weighted samples, $48.3 \%$ were male and $51.7 \%$ were female. The details of the methods are provided in a previous report. ${ }^{10}$ In this analysis, only the data on the 3009 female respondents were considered, as the male respondents had a very low response rate for IPV.

\section{Measurements}

Lifetime and the past 12-month period prevalence of psychiatric illness were assessed using the World Mental Health-Composite International Diagnostic Interview V.3.0 (WMH-CIDI 3.0). WMH-CIDI is a structured psychiatric diagnostic interview designed for use by trained interviewers. The CIDI has been widely used in epidemiological studies in many countries. The CIDI has good inter-rater reliability, test-retest reliability and validity. ${ }^{11}$ The CIDI Thai version was developed by the TNMHS group. Of the three steps of CIDI Thai version, the first step was the translation from English to Thai. The second step was pretesting and cognitive interviewing, and the third step was trial and clinical calibration described by Kittirattanapaiboon and colleagues. ${ }^{10}$ Psychiatric disorders considered in the present study included common psychiatric disorders: affective disorders (depressive disorder and mania), anxiety disorders (panic disorder, agoraphobia, generalised anxiety disorder and PTSD), psychosis screening, substance use disorders (alcohol use disorder, illegal drug use disorder) and suicide behaviours. These disorders were assessed using the definitions and criteria of the Diagnostic and Statistical 
Manual of Mental Disorders, Fourth Edition (DSM-IV) ${ }^{12}$, the International Classification of Diseases, 10th Revision (ICD-10) Classification of Mental and Behavioural Disorders ${ }^{13}$ and the World Mental Health Survey Initiative.

\section{Measurement for IPV and sexual violence}

All participants were asked about their experiences of violence in the PTSD section of the interview. In cases that the respondent experienced multiple traumas, the questions for PTSD symptoms were limited to the event that respondents judged to have been the most severe. Experiences of violence included IPV (physical abuse) and sexual violence.

Physical abuse by an intimate partner was assessed by the 'Were you ever badly beaten up by spouse or romantic partner?'. Rape was assessed by 'Did someone ever have intercourse with you or penetrate your body with a finger or object, when you did not want them to, either by threatening you or by using force?'. Sexual harassment was assessed by 'Were you ever sexually assaulted or molested?'. Sexual violence included both rape and sexual harassment.

\section{Ethical considerations}

The study proposal was approved by the ethics committee of the Department of Mental Health, a division of the Ministry of Public Health Thailand, before conducting the survey. The respondents were informed about the goals, procedures of the survey, data uses and protection and the rights of respondents, before obtaining informed consent for participating in the survey.

\section{Biostatistical analysis}

Statistical analyses were performed by R program V.3.3. We weighted the sample to account for unequal selection of probabilities in sample surveys. Base weights were used for more accurate representation of the general population and weighted for non-response, gender and age adjustment. Weighted analyses were performed as a post-stratification calibration adjustment. Detailed procedures for constructing weighted variables were reported by Kittirattanapaiboon and colleagues. ${ }^{10}$ We estimated the prevalence of IPV/sexual violence, the lifetime/ past 12-month period for diagnoses of psychiatric illness and the ORs (with 95\% CIs) of the association of these two types of violence with different types of psychiatric disorders. Logistic regression analysis was used to estimate the independent associations of the current (last 12-month period) and lifetime occurrence of different psychiatric conditions with the lifetime occurrence of the two types of violence. We also controlled for the potential confounding effects of other variables including age, education attainment, marital status and income. For the purpose of this analysis, anyone who was unemployed, earned less than 100000 baht per year or earned less than 5000 baht in the month the study was conducted was classified as 'low' socioeconomic level. ${ }^{14} \mathrm{~A}$ p-value less than 0.05 was considered statistically significant.
Table 1 Lifetime and past 12-month prevalence of intimate partner violence (IPV)/sexual violence in 3009 adult female residents of Thailand

\begin{tabular}{|c|c|c|c|c|}
\hline \multirow{2}{*}{$\begin{array}{l}\text { Types of } \\
\text { violence }\end{array}$} & \multicolumn{2}{|c|}{$\begin{array}{l}\text { Past 12-month } \\
\text { prevalence }\end{array}$} & \multicolumn{2}{|c|}{ Lifetime prevalence } \\
\hline & $\mathbf{n}$ & $\%(\mathrm{SE})^{\star}$ & $\mathbf{n}$ & $\%$ (SE)* \\
\hline IPV & 6 & $0.2(0.1)$ & 129 & $3.5(0.6)$ \\
\hline Sexual violence & 4 & $0.4(0.2)$ & 52 & $2.0(0.4)$ \\
\hline $\begin{array}{l}\text { IPV or sexual } \\
\text { violence }\end{array}$ & 10 & $0.6(0.2)$ & 170 & $5.2(0.8)$ \\
\hline Both types & 0 & 0 & 11 & $0.3(0.1)$ \\
\hline
\end{tabular}

*Proportions weighted to be representative of all adult females in Thailand.

The aim of the present study was to estimate the prevalence of IPV, sexual violence and the association between these forms of violence and psychiatric disorders.

\section{RESULTS}

\section{Prevalence of IPV and sexual violence}

As shown in table 1 , only $5.2 \%$ of the weighted sample reported to have a lifetime experience of some form of violence, including $3.5 \%$ with IPV and $2.0 \%$ with sexual violence. Only $0.3 \%$ of women reported experiencing both IPV and sexual violence over their lifetime. The reported rates of the current (i.e., the last 12-month period) IPV and sexual violence were very low, $0.2 \%$ and $0.4 \%$, respectively.

Table 2 shows the demographic data among different types of violence. The data showed that younger women ( $<25$ years), who graduated with a higher educational level and were poor (income $\leq 5000 \mathrm{baht} / \mathrm{month}$ ), experienced sexual violence more than the older age groups, that had only a primary education or less and had a higher income. Older women, with only a primary education or less, reported to have more exposure to IPV than younger women and those who graduated with a higher educational level. The prevalence of violence was higher in the Central and Northeastern regions of Thailand, but it was not found to be statistically significant (table 2).

\section{Association between psychiatric disorders and IPV/sexual violence}

As shown in table 3, women who had experienced IPV during their lifetimes had a lifetime prevalence for common psychiatric disorders of $28.9 \%$, for suicidal behaviours of $12.2 \%$ and for substance use disorders of $8.8 \%$. Women who had experienced sexual violence during their lifetimes had a lifetime diagnoses for common psychiatric disorders of $21.4 \%$, for suicide behaviours of $16.5 \%$ and for substance use disorders of $19.4 \%$. Both lifetime IPV and sexual violence were positively associated with the lifetime occurrence of psychiatric disorders, suicidal behaviours and substance abuse; lifetime IPV was also positively associated with the current 
Table 2 General information and types of violence experienced by 3009 adult female residents of Thailand

\begin{tabular}{|c|c|c|c|c|c|c|}
\hline \multirow[b]{2}{*}{ Characteristics } & \multicolumn{3}{|c|}{ Lifetime intimate partner violence } & \multicolumn{3}{|c|}{ Lifetime sexual violence } \\
\hline & $\begin{array}{l}\text { No } \\
\text { n }(\%)^{\star}\end{array}$ & $\begin{array}{l}\text { Yes } \\
\text { n }(\%)^{*}\end{array}$ & P-values $†$ & $\begin{array}{l}\text { No } \\
\text { n }(\%)^{*}\end{array}$ & $\begin{array}{l}\text { Yes } \\
\text { n }(\%)^{*}\end{array}$ & P-values \\
\hline $18-24$ & $130(99.0)$ & $3(1.0)$ & 0.04 & $125(93.9)$ & $8(6.1)$ & $<0.001$ \\
\hline$\geq 25$ & $2750(96.1)$ & $126(3.9)$ & & $2832(98.6)$ & $44(1.4)$ & \\
\hline >Primary & 1057 (97.5) & $27(2.5)$ & & $1056(97.1)$ & $28(2.9)$ & \\
\hline \multicolumn{7}{|l|}{ Marital status } \\
\hline Married & $1808(96.8)$ & $66(3.2)$ & 0.17 & 1844 (97.9) & $30(2.1)$ & 0.70 \\
\hline $\begin{array}{l}\text { Separate/Divorced / } \\
\text { Widowed/Single }\end{array}$ & $1072(95.8)$ & $63(4.2)$ & & $1113(98.1)$ & $22(1.9)$ & \\
\hline$>5000$ & $1116(96.5)$ & $44(3.5)$ & & 1145 (99.2) & $15(0.8)$ & \\
\hline \multicolumn{7}{|l|}{ Region } \\
\hline Bangkok & $489(96.7)$ & $20(3.3)$ & 0.81 & $500(98.6)$ & $9(1.4)$ & 0.23 \\
\hline Central & $640(96.0)$ & $35(4.0)$ & & $663(98.0)$ & $12(2.0)$ & \\
\hline North & $611(96.6)$ & $28(3.4)$ & & 634 (99.2) & $5(0.8)$ & \\
\hline Northeast & $560(96.9)$ & $24(3.1)$ & & $570(96.7)$ & $14(3.3)$ & \\
\hline South & $580(96.3)$ & $22(3.7)$ & & 590 (98.2) & $12(1.8)$ & \\
\hline Total & $2880(96.5)$ & 129 (3.5) & & 2957 (98.0) & $52(2.0)$ & \\
\hline
\end{tabular}

*Proportions weighted to be representative of all adult females in Thailand.

$\dagger P$ value for Rao-Scott modified $X^{2}$.

(last 12 months) occurrence of a psychiatric disorder; and lifetime experience of sexual violence was positively associated with both lifetime occurrence of psychiatric disorders and suicidal behaviour.

The logistic regression analysis shown in table 4 assessed the independent association of lifetime IPV, lifetime sexual violence, age group ( $18-24$ vs $\geq 25$ ), marital status, educational level and income level with the current (i.e., last 12 months) and lifetime occurrences of any psychiatric disorder, suicidal behaviour and substance use disorder. The results were as follows: (1) age group was unrelated to the occurrence of any of the three conditions; (2) women who were not currently married were significantly more likely to have a current psychiatric disorder or substance use disorder; (3) women with more than primary school education were less likely to have suicidal behaviour in the past year; (4) women with higher incomes (i.e., more than 5000 baht per month) were less likely to have a current or lifetime psychiatric disorder, but they were more likely to have a lifetime history of suicidal behaviour; (5) after adjusting for the other factors in the model, women with a lifetime history of IPV were significantly more likely to have a lifetime history of a psychiatric disorder, suicidal behaviour and a substance use disorder and (6) after adjusting for the other factors in the model, women with a lifetime history of exposure to sexual violence were significantly more likely to have a current and lifetime history of a psychiatric disorder or of suicidal behaviour.

\section{DISCUSSION}

Main findings

The prevalences of IPV and sexual violence in the adult Thai women identified in this study are lower than expected. The lifetime experience of IPV was significantly associated with lifetime diagnoses of common psychiatric disorders, suicide behaviours and alcohol/illicit drug use disorders. There were also statistically significant associations between the lifetime experience of sexual violence and a current or past diagnosis of a psychiatric illness or prior suicidal behaviour, but not with a current or prior diagnosis of a substance use disorder.

\section{The prevalence of IPV/sexual violence}

The present study is based on the results of a nationally representative study of community-dwelling adults 18 years of age and older in Thailand. The identified prevalences for both IPV and sexual violence were much lower than what were reported in prior studies in Thailand. For example, Jirapramukpitak ${ }^{8}$ sampled young Thai people (aged 16-25) from the Rangsit catchment area using a 


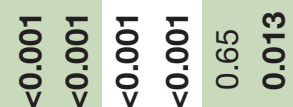

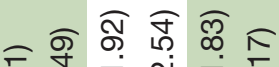
ळ

웅ㅇㅇㅇㅇㅇㅇ ก Е त ल

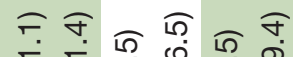

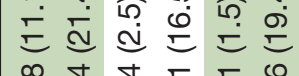

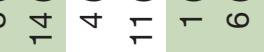

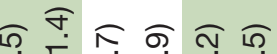

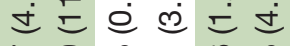

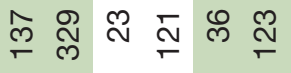

品

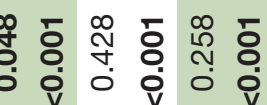

אָ क

लं

0 o 100 different measure and outcome and reported a prevalence of any type of violence of $11.7 \%$ (vs $5.2 \%$ in this study) and a prevalence of physical violence of $5.8 \%$ (vs $2.0 \%$ in our study). Our findings are also lower than that of the supportive study of a young Thai population (aged 16-25) by Jirapramukpitak. ${ }^{9}$ Compared with the WHO multi-country study on woman's health and domestic violence against women (aged 15-49), with the Thai components both 'in city' and 'in province', our findings also suggest a lower rate of violence. ${ }^{3}$ In the same survey, 'in city' women reported serious physical violence of $4 \%-8 \%$ and 'in province' of $5 \%-10 \%$. Non-partner sexual violence rates among women under and over the age of 15 were 'in city' of $8 \%$ and $6 \%$ and 'in province' of $5 \%$ and $3 \% .{ }^{15}$ Compared with the studies on non-partner sexual violence in Asian countries, our results show a slightly lower prevalence for sexual violence than the other studies reported by Abrahams ${ }^{16}(2.5 \%-6.0 \%)$, but the results were similar to the report from the International Crime Victim Survey $(0.3 \%-2.7 \%) .{ }^{17}$ Most of the women who experienced IPV did not seek professional help because they reported that these actions were common, normal and a personal matter that outsiders should have nothing to do with. ${ }^{18}{ }^{19}$ Less than $10 \%$ of the women reported that they received help from the police, the health service, monks or religious leaders. Most of them reported that they received support from friends, siblings, parents, extended family and neighbours. Of those women who were physically injured, only $25 \%$ to $33 \%$ reported that they visited the hospital, and $52 \%$ to $60 \%$ informed the staff of the cause of their injury. ${ }^{15}$ It is well known that talking about being a victim of violence can lead to feeling frightened, feeling ashamed of losing their power, low self-esteem and being stigmatised, which may have made it difficult for these victims to share their stories. $^{20} 21$ Psychological embarrassment and shame can play a major role in the under-reporting of violence against women. In the present study, respondents may have reported only serious incidents.

Demographic and social characteristics (including gender, marital status, education attainment, age and poverty) that are correlated with physical violence have been explored in several studies in similar populations. Age has occasionally been noted to be a risk factor for IPV, with a greater risk to the youth. ${ }^{22}{ }^{23}$ Moreover, younger women are usually found to be more at risk for rape than older women. ${ }^{24}$ Consistent with other studies, we found that younger women experienced sexual violence more than older women, but contrast to IPV, the older age group was significantly associated with IPV. The relation with marital status varies setting and the extent to which women have premarital and/or extramarital sexual relationships. Where premarital sex is the norm, marital status is not associated with violence. ${ }^{22}$ Consistent with other studies, we found that marital status was not associated with either IPV or sexual violence. ${ }^{24}{ }^{25}$ Coker $^{26}$ found that more violence is reported for a past relationship to a current one. Our data showed that women who graduated 


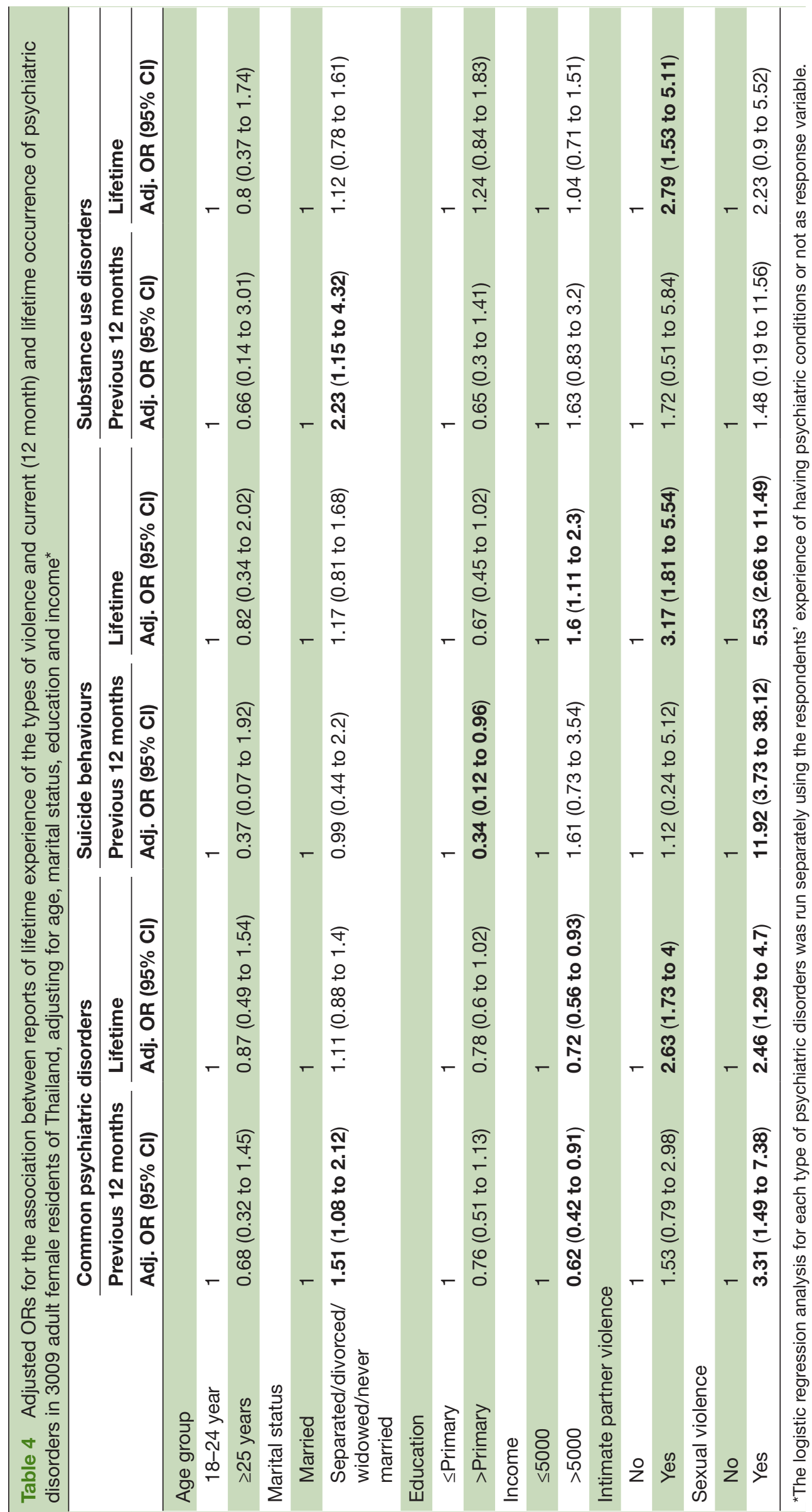

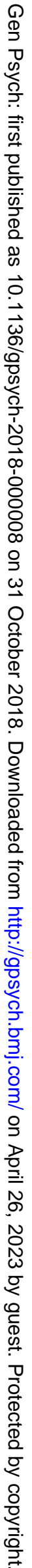


with a primary education or lesswere more likely to experience IPV more than those who had obtained a higher educational level, but sexual violence was reported more in those with a higher educational level. Our finding is a contradiction to a 1998 study of domestic violence ${ }^{27}$ that higher educational attainment of women was associated with lower levels of sexual violence. However, our finding is consistent with these studies of forced sex and rape. ${ }^{24} 28$ Thus, it is important to consider that in those women who are more educated and economically empowered, sexual violence is of a significant concern. ${ }^{24}$ Although violence occurs in all socioeconomic status (SES) groups, it is more frequent and severe in the lower SES group. The relation between poverty and IPV is that it is mediated through stress. ${ }^{22}$ Our data showed that the poor reported more exposure to sexual violence than those who earned higher incomes, but it was not associated with those who reported IPV.

\section{Association between psychiatric disorders and IPV/sexual violence}

These review studies indicated a direct positive association between the experience of IPV and psychiatric disorders. ${ }^{29} 30{ }^{31}$ Consistent with other studies, our findings suggested that IPV was significantly associated with lifetime diagnoses of common psychiatric disorders, suicidal behaviours and alcohol/illicit drug use disorders, but not associated in the past 12-month period. Sexual violence has been associated with a number of mental health and behavioural problems during adolescence reaching into adulthood. ${ }^{6}{ }^{32}$ It is similar to other studies that, after controlling for confounding factors, our data showed statistically significant associations between sexual violence and a diagnosis of psychiatric illness for both lifetime and the past 12-month period, and especially for suicide behaviours (12 times more frequent) in the past 12-month period and (6 times more frequent) in their lifetime. There was no statistically significant association between sexual violence and substance use disorders in both the past 12-month period and for their lifetime (table 3). This finding does not correlate with general clinical practice knowledge. It is probably related to the very low reported rate of both substance use and IPV/sexual violence in the past 12-month period. In addition, the Thai National Mental Health Survey 2013 results showed that women had a low prevalence of substance use disorders, $6.0 \%$ for lifetime prevalence and $1.7 \%$ for the past 12-month period prevalence. ${ }^{33}$ Our study's finding of no correlation between IPV/sexual violence and substance use may be due to the instrument we used (see the Limitations section below), as well as our study was not designed to explain the cause and effect relationship between IPV/ sexual violence and psychiatric disorders. This could be investigated in a future prospective study in the exposure group. Interestingly, our data showed a very low lifetime and past 12-month period prevalence estimate for IPV and sexual violence alone. This was understood to be a result of the small number of adults responding positively in our sample, which may have been secondary to reporting bias (table 1 ).

\section{Limitations}

The present study had several limitations. First, the measurements for violence used the items in the PTSD section of the WMH-CIDI 3.0 which only has a few items relevant to IPV (possibly resulting in under-reporting) and in which the questions regarding rape are ambiguous about who the perpetrator is (an intimate partner or someone else). Moreover, questions in the WMH-CIDI 3.0 about problems caused by the use of substances did not specifically ask about violence towards a spouse or intimate partner. As is true in all face-to-face surveys, the sensitivity about IPV, sexual violence, substance abuse, suicide and psychiatric disorder probably resulted in under-reporting of these experiences and symptoms; the use of an anonymous method to obtain these data may have resulted in higher reported rates. Recall bias is also a problem, particularly for the reports of lifetime occurrence of violence and mental health problems. ${ }^{34}{ }^{35}$ Finally, the $74 \%$ response rate is satisfactory, but it is possible that the prevalence and correlates of IVP and sexual violence in the $26 \%$ of eligible respondents who did not participate may be different from those who did participate.

\section{Implications}

Psychiatric conditions are common in individuals who have experienced IPV or sexual violence. Assessment of persons with psychiatric conditions, suicidal behaviours and substance use disorders should always be screened for present or past IPV and sexual violence. Conversely, individuals identified as victims of IPV or sexual violence should always be screened for the current or prior occurrences of psychiatric disorders, suicidal behaviours and substance use disorders. Individuals with a current condition or history of both conditions need to be provided with services that simultaneously address both issues.

Acknowledgements This survey was supported by The Department of Mental Health, Thailand. The authors wish to thank the Thai National Mental Health Survey 2013 Team for their help in conducting the study and thank Dr Tawanchai Jirapramukpitak for providing statistical, methodological and writing advice.

Contributors BP fully participated in this study in the areas of study conceptualisation, study design and tool development (Thai version). She also participated in the drafting and manuscript revision. NT fully participated in this study in the areas of study design, data analysis and interpretation. RRDB participated in this study in the areas of study design, editing of important material and language.

Funding This survey was funded by the Department of Mental Health, Ministry of Public Health. Informed consent: the respondents were informed about the goals, procedures of the survey, data uses and protection and the rights of respondents, before obtaining informed consent for participating in the survey.

Competing interests None declared.

Patient consent Obtained.

Ethics approval Our survey was approved by the ethics committee of the Department of Mental Health, Ministry of Public Health.

Provenance and peer review Not commissioned; externally peer reviewed.

Open access This is an open access article distributed in accordance with the Creative Commons Attribution Non Commercial (CC BY-NC 4.0) license, which 
permits others to distribute, remix, adapt, build upon this work non-commercially, and license their derivative works on different terms, provided the original work is properly cited and the use is non-commercial. See: http://creativecommons.org/ licenses/by-nc/4.0

\section{REFERENCES}

1 World Health Organization. Global status report on violence prevention. Geneva: WHO, 2014.

2 Ulrich YC, Cain KC, Sugg NK, et al. Medical care utilization patterns in women with diagnosed domestic violence. Am J Prev Med 2003;24:9-15.

3 Garcia-Moreno C, Jansen HA, Ellsberg M, et al. Prevalence of intimate partner violence: findings from the WHO multi-country study on women's health and domestic violence. Lancet 2006;368:1260-9.

4 United Nations Office on Drugs and Crime. Global study on homicide 2013. Vienna: UNODC, 2014

5 Golding JM. Intimate partner violence as a risk factor for mental disorders: A meta-analysis. J Fam Violence 1999;14:99-132.

6 Chen LP, Murad MH, Paras ML, et al. Sexual abuse and lifetime diagnosis of psychiatric disorders: systematic review and metaanalysis. Mayo Clin Proc 2010;85:618-29.

7 Devries KM, Mak JY, Bacchus LJ, et al. Intimate partner violence and incident depressive symptoms and suicide attempts: a systematic review of longitudinal studies. PLoS Med 2013;10:e1001439.

8 Jirapramukpitak T, Prince M, Harpham T. The experience of abuse and mental health in the young Thai population A preliminary survey. Soc Psychiatry Psychiatr Epidemiol 2005;40:955-63.

9 Jirapramukpitak T, Abas M, Harpham T, et al. Rural-urban migration and experience of childhood abuse in the young Thai population. $J$ Fam Violence 2011;26:607-15.

10 Kittirattanapaiboon P, Tantirangsee N, Chutha W. Thai national mental health survey 2013: Methodology and procedure. J Ment Health Thai 2016;24:1-14.

11 Haro JM, Arbabzadeh-Bouchez S, Brugha TS, et al. Concordance of the Composite International Diagnostic Interview Version 3.0 (CIDI 3.0) with standardized clinical assessments in the WHO World Mental Health surveys. Int J Methods Psychiatr Res 2006;15:167-80.

12 American Psychiatric Association. The diagnostic and statistical manual of mental diso rders. 4th edn. Washington, DC: American Psychiatric Association, 2000.

13 World Health Organization. The ICD-10 classification of mental and behavioral disorders: clinical descriptions and diagnostic guidelines. Geneva: World Health Organization, 1992.

14 Finance Ministry, 2017. Pracha Wiwat Welfare Project. WWW. epayment.go.th (Accessed 1 May 2017).

15 Archavanitkul K, Kanchanachitra C, Im-em W. Intimate partner violence and women health. Nakhon Pathom: Mahidol University. Research report 2003.

16 Abrahams N, Devries K, Watts C, et al. Worldwide prevalence of non-partner sexual violence: a systematic review. Lancet 2014;383:1648-54.
17 World Health Organization. Sexual violence. in: world report on violence and health. Geneva: WHO, 2002.

18 Pradabmuk T. Family violence: state of the art review and research promoting system in the future. Nontaburi: Health System Research Institute, 2003.

19 Laeheem K, Boonprakarn K. Domestic violence behaviors between spouses in Thailand. Asian Soc Sci 2014;10:152-9.

20 Dartnall E, Jewkes R. Sexual violence against women: the scope of the problem. Best Pract Res Clin Obstet Gynaecol 2013;27:3-13.

21 UNICEF. Violence against children in East Asia and the Pacific: a regional review and synthesis of findings. Strengthening Child Protective Synthesis Series, No.4. Bangkok: UNICEF EAPRO, 2014.

22 Jewkes R. Intimate partner violence: causes and prevention. Lancet 2002;359:1423-9.

23 Acierno R, Resnick H, Kilpatrick DG. Risk factors for rape, physical assault, and post-traumatic stress disorder in women: Examination of different multivariate relationships. J Anxiety Disorder 1999;13:541-63.

24 World Health Organization. World report on violence and health: sexual violence. Geneva: WHO, 2002: 149-81.

25 Ernst AA, Nick TG, Weiss SJ. Domestic violence in an inner-city ED. Ann Emerg Med 1997;1997:190-7.

26 Coker AL, Smith PH, McKeown RE, et al. Frequency and correlates of intimate partner violence by type: physical, sexual, and psychological battering. Am J Public Health 2000;90:553-9.

27 Jewkes R, Levin J, Penn-Kekana L. Risk factors for domestic violence: findings from a South African cross-sectional study. Soc Sci Med 2002;55:1603-17.

28 Jewkes R, Abrahams N. The epidemiology of rape and sexual coercion in South Africa: an overview. Soc Sci Med 2002;55:1231-44.

29 Trevillion K, Oram S, Feder G, et al. Experiences of domestic violence and mental disorders: a systematic review and meta-analysis. PLoS One 2012; 7:e51740.

30 Howard LM, Trevillion K, Khalifeh H, et al. Domestic violence and severe psychiatric disorders: prevalence and interventions. Psychol Med 2010;40:881-93.

31 Hovens JG, Wiersma JE, Giltay EJ, et al. Childhood life events and childhood trauma in adult patients with depressive, anxiety and comorbid disorders vs. controls. Acta Psychiatr Scand 2010;122:66-74.

32 Creamer M, Burgess P, McFarlane AC. Post-traumatic stress disorder: findings from the Australian National Survey of Mental Health and Well-being. Psychol Med 2001;31:1237-47.

33 Kittirattanapaiboon P, Tantirangsee N, Chuta W. Prevalence of mental disorders and mental health problems: Thai National Mental Health Survey 2013. J Ment Health Thai 2017;25:1-19.

34 Brewin CR, Andrews B, Gotlib IH. Psychopathology and early experience: a reappraisal of retrospective reports. Psychol Bull 1993;113:82-98.

35 Fergusson DM, Horwood LJ, Woodward LJ. The stability of child abuse reports: a longitudinal study of the reporting behaviour of young adults. Psychol Med 2000;30:529-44.

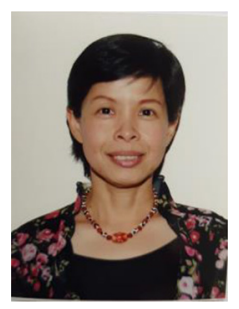

Benjaporn Panyayong obtained a bachelor degree from Prince of Songkla University in Thailand in 1982, and a diploma (Thai Board) of child and adolescent psychiatry in 1993 and another Diploma (Thai Board) of Pediatrics in Thailand in 1988. She started the Master degree program in Mental Health Leadership at University of Melbourne, Australia in 2004. Now she is working as a medical staff member at Somdet Chaopraya Institute of Psychiatry and senior consultant at the Department of Mental Health in the Ministry of Public Health, Thailand. She is also the vice-chairman of Violence Prevention and Intervention in Women and Children Committee at the department of mental health. Her research interests include disasters and mental health as well as violence and mental health. 